\title{
Hubungan Sikap Kerja dan Beban Kerja Dengan Keluhan Muskuloskeletal pada Nelayan
}

\author{
Fadillah ulva*, Gusrianti, Gusni Rahma \\ STIKes Alifah Padang \\ Jl. Khatib Sulaiman No 52 B Padang \\ *Correspondence email: dilla_afdal@yahoo.com,gusrianti@gmail.com, gusnirahma@gmail.com
}

\begin{abstract}
Abstrak. Keluhan muskuloskeletal merupakan keluhan yang terjadi pada otot skeletal yang dirasakan dengan keluhan mulai dari keluhan sangat ringan sampai keluhan sangat sakit. Keluhan musculoskeletal dapat terjadi karena adanya pembebanan pada otot secara statis dan berulang yang terjadi dalam waktu yang lama. Keluhan musculoskeletal dapat merusak sendi, ligament dan otot. Hal ini dapat menyebabkan stres kerja akibat kondisi kerja yang salah. Tujuan Penelitian ini adalah untuk mengetahui hubungan sikap kerja dan beban kerja dengan keluhan muskuloskeletal pada Nelayan. Jenis penelitian yang digunakan adalah kuantitatif dengan desain cross sectional stady. Penelitian ini dilaksanakan di Nelayan Pasia Nan Tigo Kecamatan Koto Tangah. Jumlah sampel sebanyak 30 orang. Penelitian ini menggunakan data primer dan data sekunder. Alat ukur yang digunakan yaitu kuesioner. Data di analisis secara univariat dan bivariate dengan menggunakan uji Chi Square. Berdasarkan hasil penelitian diketahui terdapat hubungan antara sikap kera (p value : 0,23 ) dan beban kerja (p value: 0,009$)$ dengan keluhan musculoskeletal.
\end{abstract}

Kata kunci: sikap kerja; beban kerja; keluhan muskuloskeletal

Abstract. Musculoskeletal complaints are complaints that occur in the skeletal muscles that are felt with complaints ranging from very mild complaints to very painful complaints. Musculoskeletal complaints can occur due to static and repetitive loading on the muscles that occurs for a long time. Musculoskeletal complaints can damage joints, ligaments and muscles. This can cause work stress due to the wrong working conditions. The purpose of this study was to determine the relationship between work attitude and workload with musculoskeletal complaints in fishermen. The type of research used is quantitative with a cross sectional stady design. This research was conducted in the Fisherman of Pasia Nan Tigo, Koto Tangah District. The number of samples is 30 people. This study uses primary data and secondary data. The measuring instrument used is a questionnaire. The data were analyzed univariately and bivariately using the Chi Square test. Based on the results of the study, it was known that there was a relationship between ape's attitude ( $p$ value: 0.23) and workload ( $p$ value: 0.009) with musculoskeletal complaints.

Keywords: musculoskeletal disorders; posture; workload

\section{PENDAHULUAN}

Indonesia sebagai Negara kepulauan membuat nelayan menjadi salah satu pekerjaan mayoritas masyarakat Indonesia. Berdasarkan Profil Data BPS tahun 2011, terdapat sekitar 8.900 desa pesisir yang tersebar 300 kabupaten/kota pesisir di Indonesia. Dari 234,2 juta jiwa penduduk Indonesia, ada 67,87 juta jiwa yang bekerja di sektor informal dan sekitar 30\% diantaranya adalah nelayan. Kegiatan yang dilakukan oleh nelayan harus sesuai dengan kondisi tubuh serta tenaga yang dimiliki oleh masing-masing individu sehingga harus ada keseimbangan antara keduanya karena akan mempengaruhi kesehatan dan kinerja manusia. Dalam melakukan pekerjaannya, Nelayan akan melakukan pekerjaan secara terus menerus dengan gerakan yang terus menerus yang akan menimbulkan terjadinya kelelahan pada otot. Kondisi seperti ini dapat mengakibatkan penyakit akbiat kerja (Sujana, 2014).

Berdasarkan data dari National Academy of Sciences (2010) diketahui bahwa 2,3 juta orang meninggal dunia akibat penyakit akibat kerja ataupun kecelakaan kerja setiap tahunnya. Selain itu, lebih dari 160 juta orang menderita penyakit akibat kerja yang berhubungan dengan pekerjaan. Salah satu penyakit akibat kerja yang disebabkan oleh lingkungan kerja yang tidak ergonomis adalah keluhan musculoskeletal disorder.

Keluhan musculoskeletal memiliki faktor risiko diantaranya: faktor individu (usia, kebiasaan merokok, kebiasaan olahraga, jenis kelamin, IMT dan masa kerja), faktor pekerjaan (frekuensi, potur kerja, berat beban durasi) dan faktor lingkungan (getaran paparan suhu). Postur kerja yang salah merupakan salah satu risiko ergonomi yang paling berpengaruh terhadap terjadinya keluhan musculoskeletal. Oleh karena itu perlu dilakukan pengukuran risiko ergonomi. Penilaian risiko ergonomic dapat dilakukan dengan berbagai metode penilaian seperti Ergonomic Assement Survey (EASY), Baseline Risk Identification of Ergonomic Faktors (BRIEF), Quick Exposure Checklist (QEC), Rapid Upper Limb Assessment (RULA), The Ovako Working Posture Analysis System (OWAS), Rapid Entire Body Assessment (REBA). Reba merupakan metode untuk menilai postur kerja seseorang ketika melakukan pekerjaannya. (Tarwaka, 2014).

Tubuh manusia dirancang untuk dapat melakukan aktivitas pekerjaan sehari-hari. Dengan melakukan pekerjaan maka tubuh akan mnerima beban dari luar 
tubuhnya. Setiap pekerja memiliki beban kerja yang berbeda-beda, sesuai dengan jenis pekerjaannya. Beban kerja dapat berupa beban kerja mental, fisik dan sosial. Beban kerja fisik merupaka beban kerja yang diakibatkan oleh kerja yang memerlukan energy fisik pada otot manusia yang akan berfungsi sebagai sumber tenaga. Setiap aktivitas kerja fisik yang dilakukan oleh pekerja akan mengakibatkan terjadinya suatu perubahan pada fungsi faal tubuh manusia yang dapat dilihat melalui berbagai indikator. (Eko, 2010).

Berdasarkan hasil penelitian dari Kementrian Kesehatan tentang masalah kesehatan di Indonesia pada tahun 2018 menunjukkan bahwa 40,5\% penyakit akibat kerja yang dialami oleh pekerja berhubungan dengan pekerjaannya. Penelitian yang dilakukan terhadap 9.482 pekerja di 12 kabupaten/kota di Indonesia menunjukkan bahwa gangguan pada musculoskeletal merupakan penyakit dengan urutan pertama (16\%) yang dialami oleh pekerja kemudian gangguan pada kardiovaskuler $(8 \%)$, gangguan pada syaraf $(6 \%)$, gangguan pernafasan (3\%) dan gangguan THT (1,5\%) (Kemenkes RI, 2018).

\section{METODE}

Penelitian ini merupakan penelitian kuantitatif menggunakan desain cross sectional study. Penelitian dilakukan di kelurahan Pasia Nan Tigo Kecamatan Koto Tangah. Populasi pada penelitian ini adalah Nelayan Pasia Nan Tigo sebanyak 30 orang, semua populasi dijadikan sampel pada penelitian ini. Data primer dalam penelitian ini didapatkan dengan metode wawancara menggunakan instrument penelitian berupa kuesioner.

\section{HASIL DAN PEMBAHASAN}

Berdasarkan hasil penelitian diketahui bahwa distribusi frekuensi responden berdasarkan keluan musculoskeletal, beban kerja, dan sikap kerja dapat dilihat pada tabel berikut

Tabel 1. Distribusi Frekuensi responden berdasarkan Sikap Kerja, Beban Kerja, dan Keluhan Muskuloskeletal

\begin{tabular}{lcc}
\hline Kategori & Frekuensi & Persentase \\
\hline $\begin{array}{l}\text { Keluhan Muskuloskeletal } \\
\quad \text { Berisiko }\end{array}$ & 11 & 36.7 \\
$\quad$ Tidak berisiko & 19 & 63.3 \\
$\begin{array}{l}\text { Beban Kerja } \\
\quad \text { Berat }\end{array}$ & 12 & 40 \\
$\quad$ Tidak berat & 18 & 60 \\
Sikap Kerja & & \\
$\quad$ Berisiko & 13 & 43.3 \\
$\quad$ Tidak berisiko & 17 & 56.7 \\
\hline
\end{tabular}

Berdasarkan hasil penelitian diketahui hubungan sikap kerja, beban kerja dengan keluhan musculoskeletal dapat dilihat pada tabel berikut
Tabel 2. Hubungan Sikap Kerja, Beban Kerja dengan Keluhan Musculoskeletal

\begin{tabular}{lcccccccc}
\hline \multirow{2}{*}{$\begin{array}{c}\text { Variabel } \\
\text { Independen }\end{array}$} & \multicolumn{9}{c}{ Keluhan Muskuloskeletal } & \multirow{2}{*}{ Jumlah } & \multirow{2}{*}{$\begin{array}{c}\text { Peresiko } \\
\text { f }\end{array}$} & $\begin{array}{c}\text { Tidak beresiko } \\
\text { f }\end{array}$ & f & \% & f & $\%$ & value \\
\hline Beban Kerja & & & & & & & \\
$\quad$ Berat & 8 & 66,7 & 4 & 33,3 & 12 & 100 & \multirow{2}{*}{0,009} \\
$\quad$ Tidak berat & 3 & 16,7 & 15 & 83,3 & 18 & 100 & \\
\hline Sikap Kerja & & & & & & & \\
$\quad$ Beresiko Rendah & 8 & 61,5 & 5 & 38,5 & 13 & 100 & \multirow{2}{*}{0,023} \\
$\quad$ Beresiko Tinggi & 3 & 17,6 & 14 & 82,4 & 17 & 100 & \\
\hline
\end{tabular}

Berdasarkan tabel dapat dilihat bahwa kejadian keluhan musculoskeletal lebih tinggi pada responden dengan beban kerja berat $(66,7 \%)$ dibandingkan pada responden beban kerja tidak berat $(16,7 \%)$. Dari hasil uji statistik Chi-Square didapatkan $\mathrm{P}$ value $0,009(\mathrm{P}<0,05)$, dapat disimpulkan bahwa terdapat hubungan yang signifikan antara beban kerja dengan keluhan muskuloskeletal pada nelayan. Berdasarkan tabel 4.5 dapat dilihat bahwa kejadian keluhan musculoskeletal lebih tinggi pada responden dengan beban kerja berat $(66,7 \%)$ dibandingkan pada responden beban kerja tidak berat $(16,7 \%)$. Dari hasil uji statistik Chi-Square didapatkan $\mathrm{P}$ value $0,009(\mathrm{P}<0,05)$, dapat disimpulkan ada hubungan yang signifikan antara beban kerja dengan keluhan muskuloskeletal pada nelayan.

Berdasarkan hasil penelitian diketahui bahwa kejadian keluhan muskuloskeletal lebih tinggi pada responden dengan sikap kerja beresiko rendah $(16,5 \%)$ dibandingkan pada responden sikap kerja beresiko tinggi sebanyak (17,6\%). Dari hasil uji statistik Chi-Square didapatkan Pvalue 0,009 $(\mathrm{P}<0,05)$, dapat disimpulkan ada hubungan yang signifikan antara beban kerja dengan keluhan muskuloskeletal pada nelayan.

Hasil penelitian ini menunjukkan bahwa nelayan yang mempunyai keluhan muskuloskeletal dengan kategori berat $(40,0 \%)$ sebanyak 12 orang sedangkan yang beban kerjanya kategori ringan $(60,0 \%)$ sebanyak 18 orang. Beban kerja yang dirasakan oleh pekerja tersebut di karenakan faktor lingkungan seperti panas dan ombak yang kuat. Hasi analisis bivariat pada penelitian ini ada hubungan yang signifikan antara beban kerja dengan keluhan muskuloskeletal pada nelayan.

Dalam penelitian ini variabel sikap kerja digolongkan kedalam dua kategori yaitu sikap kerja beresiko $(\geq 7)$ dan sikap kerja tidak beresiko $(<7)$. Dari 30 responden, 19 responden $(63,3 \%)$ sikap kerja tidak beresiko. Dan 11 responden $(36,7 \%)$ yang sikap kerjanya beresiko. Hasil analisis bivariat hubungan variabel sikap kerja dengan keluhan muskuloskeletal diketahui bahwa ada hubungan yang signifikan antara sikap kerja dengan keluhan muskuloskeletal.

Pada penelitian ini, terdapat hubungan antara posisi kerja dengan kejadian keluhan muskuloskeletal dikarenakan posisi statis pada postur badan dari nelayan tidak sesuai atau tidak nyaman saat bekerja. Hal ini juga diperburuk dengan adanya faktor lingkungan yang tidak stabil, yang akan berakibat terjadinya kelelahan yang dirasakan oleh nelayan akibat kelelahan pada otot 
skeletal khususnya otot punggung bawah. Hal ini dapat berdampak buruk bagi kehidupan nelayan tersebut dan pada masyarakat umumnya.

\section{SIMPULAN}

Berdasarkan hasil penelitian dapat disimpulkan lebih dari separuh nelayan $(63,3 \%)$ mengalami keluhan muskuloskelektal yang tidak beresiko pada nelayan, lebih dari separuh nelayan $(60,0 \%)$ yang beban kerjanya tidak berat pada nelayan, lebih dari separuh nelayan $(56,7 \%)$ yang sikap kerjanya tinggi pada nelayan. Adanya hubungan sikap kerja ddan beban kerja dengan keluhan muskuloskelektal pada nelayan.

Disarankan agar nelayan dapat melakukan pekerjaan dengan memperhatikan sikap kerja yang ergonomis guna mengurangi risiko munculnya keluhan musculoskeletal pada nelayan. Selain itu juga perlu dilakukan pendidikan kesehatan yang berkelanjutan pada nelayan sehingga dapat terciptanya perilaku kerja yang ergonomis.

\section{DAFTAR PUSTAKA}

Eko Nurmianto, 2010. Ergonomi konsep dasar dan aplikasinya. Surbaya: gunawidya

KemenKes RI, 2018. Profil Masalah Kesehatan Indonesia. Jakarta.

National Academy of Science, 2010. Health and safety statistics. Washington DC: The National Academy Press.

Sujana, 2014. Hubungan Sikap Kerja Dengan Keluhan Mukuloskeletas Pada Penyakit Tembakau Digudang sortasi tembakau kebun klumpang PTPN 2 tahun 2015. Jurnal Kesehatan Masyarakat. Vol 2. Hal: 96-97.

Tarwaka, Solichul H, Bakri A, dan Sudiajeng, Lilik, 2014. Ergonomi UntukKesehatan dan keselamatan Kerja dan Produktivitas. Surakarta: Uniba Press. 